\title{
Разработка игры «Сахалыы таайбаран» посредством объектно-ориентированного языка программирования Delphi 7.0
}

\author{
Алексеева Е.А., студент, \\ Вилюйский педагогический колледжс им. Н.Г. Чернышевского, \\ 2. Вилюйск
}

\section{Научный руководитель:} Васильева Н.В.

Актуальность нашей работы заключается в том, что в последние годы сфера применения якутского языка стала сужаться, что ведет к постепенной утрате значения языка. Такое печальное явление наблюдается среди школьников, молодежи, среднего и даже пожилого возрастов, проживающих в городах и улусных центрах.

Подрастающее поколение не может использовать родной язык в полном объеме в повседневной жизни, более того некоторые не умеют читать и писать на родном языке. В настоящее время словарный запас у молодых людей заметно обеднел, таким образом, они отходят от родной культуры и традиций. Кроме того, дети школьного возраста и молодежь стали много увлекаться зарубежными компьютерными играми. Потому, что в Якутии очень мало игр с познанием якутского языка и культуры народов Саха. Исходя из этого, мы перед собой поставили цель: разработать якутскую игру «Сахалыы таайбаран» посредством объектно-ориентированного языка программирования Delphi 7. Для достижения данной цели установили следующие задачи: изучить специальную литературу по данной теме; изучить основные понятия якутской игры «Сахалыы таайбаран»; разработать якутскую игру «Сахалыы таайбаран». При разработки игры мы выбрали объектно-ориентированный язык Delphi 7.0. Изучили и освоили данный язык.

Перед разработкой игры все картинки-подсказки, фоны, кнопки и буквы я сама нарисовала вручную в программном обеспечении Adobe Photoshop Professional CS6 (рисунок 1,2,3).

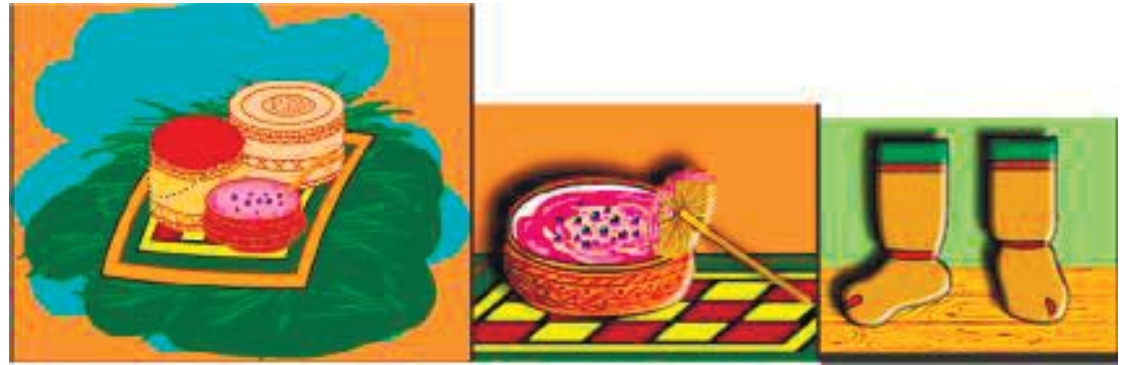

Рис. 1. Изображения заданий игры

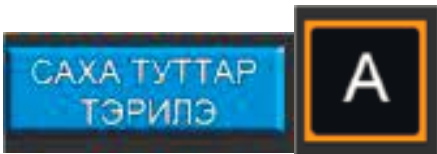

Рис. 2. Изображения кнопок игры

Запускаем Delphi 7.0. и нажимаем на кнопку SaveAll (Сохранить). Выбираем нашу папку под названием «Сахалыы таайбаран». Нажимаем на кнопку Сохранить. 
Подстроим нашу форму под необходимый нам размер. Ширина 800 высота 600.Объявляем все необходимые переменные: графический буфер, сел, фоны, картинки-подсказки, форматы bmp и jpg, буквы, кнопки, режимы, активы, уровни, слова, оригинальное слово, угаднное слово, процедура новый уровень, пути к папке.Указываем пути всех картинок. Начнем с активации кнопок. Кликаем по Events (События), находим вкладку OnMouseMove (прописываем координаты когда вводим мышкой над формой).Проверяем игру, активация кнопок работает но не работает клики по ним. Для этого чтобы работали кликиНаходим вкладку OnMouseDown (Нажимаем мышкой форму) и пишем след код.Проверяем игру и когда нажимаем на кнопку выход то автом выходит А когда нажимаем на другие кнопки анимация больше не работает. Потому, что у нас на экране остается последняя нарисованная картинка. Поэтому вернемся к нашему таймеру и пишем след код. Как видно на картинке загрузились наша картинка-подсказка, пустые ячейки, необходимые буквы снизу, а также наша кнопка выхода в главное меню. Но когда мы кликаем по ним, то ничего не действует.

Поэтому сейчас нам нужно перейти к обработке кликов. Для этого опять же кликаем по Events (События), находим вкладку OnMouseDown (Нажимаем мышкой форму) и пишем код. Теперь давайте проверим нашу игру, для этого нажимаем на F9.

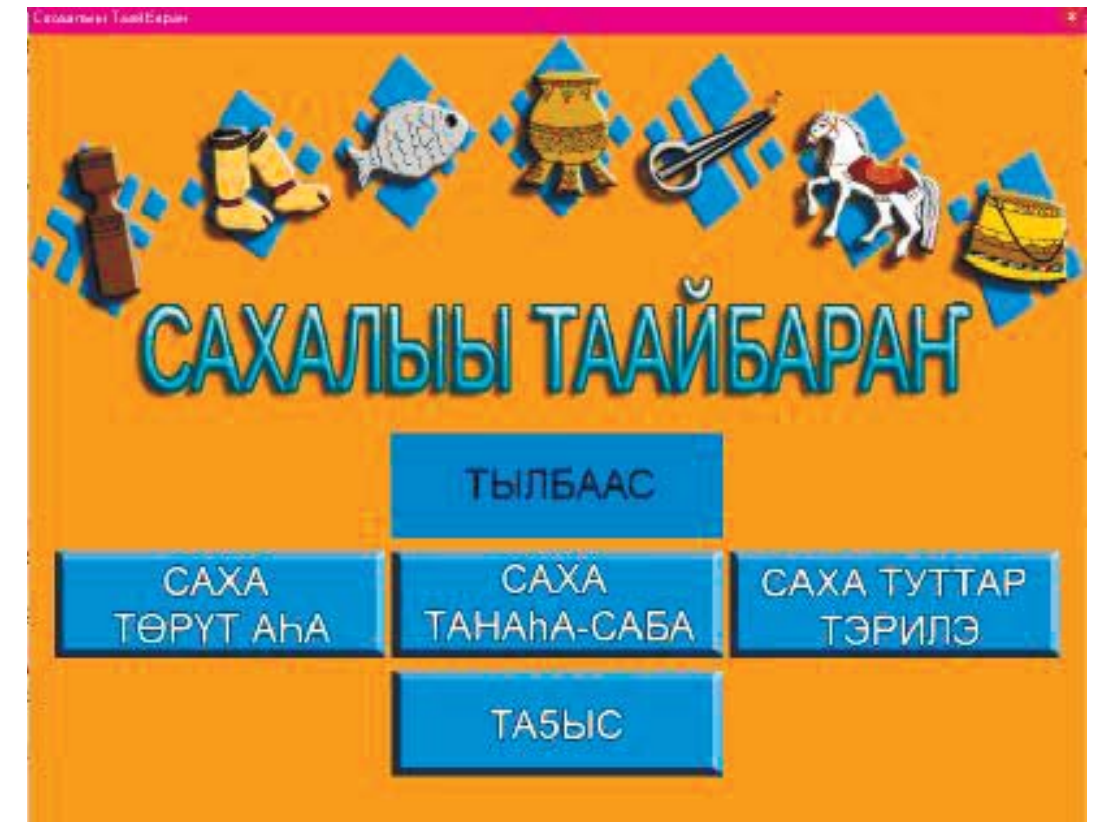

Рис. 3. Общий вид игры «Сахалыы таайбаран»

Наша игра работает, не выводит никаких ошибок. Цель и задачи, поставленные в работе, выполнены. Изучили литературу по данной теме, уточнили основные понятия культуры народов саха, разработали игру «Сахалыы таайбаран».

Подводя итоги, следует отметить, что важнейшей составной частью культуры народов саха является якутская еда, одежда и самодельные инструменты быта. Исходя из этого, при разработки игры, мы включили разделы: словарь с иллюстрацией и три категории игры, вышеуказанные темы.

Данную игру «Сахалыы таайбаран» мы разработали по средством объектноориентированного языка программирования Delphi 7. В процессе работы был изучен и освоен язык программирования Delphi 7. В работе мы показали один из возможностей объектно-ориентированного языка Delphi 7 по разработке игры, в нашем случае «Сахалыы таайбаран». 
Игра состоит из трех категорий: «Саха төрүт аһа», «Саха танаһа-саба», «Саха туттар тэриллэрэ» и отдельно краткий словарь с иллюстрацией на трех языках: якутский, русский и английский.

Данную игру могут использовать учителя культуры народов Республики Саха (Якутии) при закреплении изученного материала, а также в свободное время все желающие.

Список литературы:

1. Афанасьев П.С. Саха тылын быьаарыылаах кылгас тылдьыта. Дьокуускай,1994.

2. Данилов В.Н. Русско-якутский тематический словарь. Якутск, 1988. 44 с.

3. Зверева А.Н. Узоры земли олонхо. СПб., 2015. 78 с.

4. Иванова С.Р. Саха танаһа. Якутск, 1993. 3 с.

5. Петрова Т.И. Краткий якутско-русский словарь. Якутск, 2006. 48 с.

6. Попов И.К. Саха тылыгар кылгас комо тылдьыт. Дьокуускай, 2004.

7. Саввинов А.И. Якутская коллекция в Линден - музее Штутгарта. Якутск, 2009. $52 \mathrm{c}$.

8. Томская М.П. Уран тарбах тардыыта. Дьокуускай, 2011. 12 с.

9. Окулов С.М. Основы программирования. М., 2004. 424 с.

10. Бабушкина И.А. Практикум по объектно-ориентированному программированию. М., 2004. 366 с.

11. Окулов С.М. Программирование в алгоритмах. М., 2002. 341 с.

12. Голицына О.Л., Попов И.И. Основы алгоритмизации и программирования. M., 2005. 432 c.

13. http://ru.wikipedia.org/delphi

14. http://www.interface.ru

15. http:// life-prog.ru/view_cat.php?cat=12

16. http://rsdn.org/?article/Delphi/Delphi_7_01.xml

17. http://www.compbegin.ru/articles/view/_114

18. http://ru.wikipedia.org/wiki/Adobe_Photoshop

\title{
3D моделирование в промышленности
}

\author{
Аммосов А.В., студент, \\ Технический институт (филиал) \\ Северо-Восточного федерального университета, \\ 2. Нерюнгри \\ E-mail: mad_dr.charli@mail.ru
}

Научный руководитель: к.n.н., зав. кафедрой МиИ Самохина В.М.

В настоящее время все больше инновационных технологий внедряются в повседневную жизнь человека. То, что раньше считалось технологией будущего можно уже встретить в промышленности. 